This is an author's version of a chapter published in Complicated Grief: Scientific Foundations for Health Care Professionals. Stroebe, M., Schut, H., Boelen, P. \& van den Bout, J. (eds.) Routledge. (2012) pp.13-26. https://www.routledge.com/Complicated-Grief-ScientificFoundations-for-Health-Care-Professionals/Stroebe-Schut-Bout/p/book/9780415625050

\title{
Complicated Grief: Philosophical Perspectives
}

\section{Rachel Cooper}

This chapter examines how work in the philosophy of medicine, philosophy of science and moral philosophy can help elucidate the concept of complicated grief. The chapter addresses two key questions: First, what is disorder? I examine various accounts from the philosophy of medicine, ranging from the purely descriptive account proposed by Boorse (1975, 1976, 1977, 1997), who argues that disorders are biological dysfunctions, through to accounts that claim that disorder is a value-laden concept and that disorders are necessarily bad. In each case, I examine implications for the concept of complicated grief. On some accounts, normal grief might itself be considered a disorder, and so at points considering whether complicated grief is a disorder becomes entwined with considering whether normal grief is a disorder. As such, in the first part of this paper, I consider the following issues: Does complicated grief involve a biological dysfunction? Is grief a bad thing, or a necessary part of the good human life? Can normal grief and complicated grief be clearly distinguished? Might we think of normal grief as being a "mental injury" analogous to physical injury?

Second, I will examine how work in the philosophy of science might contribute to debates over whether complicated grief should be considered a distinct disorder, or whether it should be considered a mere variant of some other condition, for example, Major Depressive Disorder, Post Traumatic Stress Disorder or Adjustment Disorder. Here I will set out philosophical work on the role of classification in science, and show how it can contribute to determining the conditions under which we should conclude that complicated grief is a distinct kind of disorder. 


\section{Part 1 - What is a disorder? Is complicated grief a disorder?}

Philosophers have written little that explicitly addresses the issue of whether complicated grief should be considered a disorder. However, there is a large body of work on the concept of disorder that can be directly applied to this issue. In the philosophy of medicine, accounts of disease, disorder or illness (in the literature the terms tend to be used interchangeably) can be split into two main camps. On the one hand, there are descriptivists, who claim that whether a condition is a disorder is purely a matter of biological fact. On the other hand, there are normativist positions, which claim that whether a condition is a disorder depends, at least in part, on whether it is a bad thing.

The best known descriptivist account has been proposed by Boorse (1975, 1976, 1977, 1997). In a range of publications, Boorse has proposed that a condition is a disorder if and only if it is a biological dysfunction. His basic idea is that the bodies and minds of human beings can be thought of as consisting of numerous subsystems - such as organs, mental modules, and more diffuse systems, such as the system made up of blood vessels. Each subsystem has a particular natural function, which is whatever it normally does that contributes to the organism's overall goals of reproduction and survival. For example, the function of the eye is to enable sight, and the function of the heart is to pump blood round the body. When we are healthy each of our subsystems fulfils its function. But when we suffer from a disorder one or more subsystems fails to function at a level that is average for comparative organisms (i.e. the subsystem functions at a level significantly below that which we might expect given our age and sex).

Boorse's account is attractive in so far as it accounts for a number of commonplace intuitions. On Boorse's account, whether there is a disorder depends simply on natural biological facts, and medics will thus be best qualified to determine whether a condition is a disorder.

Despite its attractions, however, Boorse's account faces problems and has been heavily criticised. The biggest difficulty for a Boorse-style account is that many people have a strong intuition that disorders must necessarily be bad. As he proposes a purely descriptive account Boorse cannot accommodate this intuition. For Boorse, whether a condition is a disorder comes down to a purely biological question; if there a biological dysfunction there is a disorder and whether the condition is a bad thing is irrelevant. Tensions over this point came to a head in discussions about homosexuality (Bayer, 1981). During the 70s the question of whether homosexuality is pathological was heavily debated. On Boorse's account the question hinges on whether homosexuality involves some 
biological dysfunction. The possibility of kin-selection effects and other atypical selection mechanisms mean that answering this question is far from straightforward. In any case it seemed to many that questions about the biological significance of homosexuality missed the genuine issue. To many, the key question in addressing whether homosexuality is pathological is whether homosexuality is harmful; in so far as homosexuality is not a bad thing it cannot be a disorder, and questions about biological functioning seem irrelevant.

Following these debates, Wakefield proposed his highly influential account of disorder (1992a, 1992b, 1993, 1999, this volume). Wakefield's account sets out to accommodate the intuition that a condition can only be a disorder if it is bad. On his account, disorders are harmful dysfunctions, where whether a condition is harmful is to be determined by current social norms. For Wakefield, whether or not homosexuality is a dysfunction, in so far as it is not harmful, it will not be a disorder. Wakefield's account has been hugely influential. Key figures involved in the construction of the DSM (the classification of mental disorders produced by the American Psychiatric Association) have written of their admiration for his account, and indeed suggest that explicitly adopting Wakefield's account might helpfully guide future revisions to the classification system (Spitzer, 1999) .

For Boorse, if one wants to know whether complicated grief is a disorder one should ask whether it is a biological dysfunction. For Wakefield, in order to be a disorder, complicated grief would both need to involve some evolutionary dysfunction and also be harmful.

Boorse hasn't written about grief, but Wakefield considers normal grief and complicated grief in a number of his writings. Writing together with Horwitz in The Loss of Sadness: How Psychiatry Transformed Normal Sorrow into Depressive Disorder (2007), Wakefield argues at length that forms of normal sadness, amongst which he includes normal grief, must be distinguished from depression. Using his account of disorder, he suggests that while both normal sadness and depression may be harmful, normal sadness involves no biological dysfunction, and should thus not be classed as disorder, while true depression does involve dysfunction and thus counts as disorder. Why do Horwitz and Wakefield think that normal sadness is normal functioning? Because they think that there is an evolutionary explanation for those feelings of sadness that arise in appropriate circumstances. Normal feelings of sadness can be identified as

\footnotetext{
${ }^{1}$ Despite this endorsement of Wakefield's account, there are good reasons for thinking that the DSM has not actually employed an evolutionary account of dysfunction. As Bolton (2008, pp139-151) points out, Wakefield's account is of limited practical use as in most cases of mental disorder whether or not there is an evolutionary dysfunction remains unclear.
} 
... they emerge because of specific kinds of environmental triggers, especially loss; they are roughly proportionate in intensity to the provoking loss; and they end when the loss situation ends or gradually cease as natural coping mechanisms allow an individual to adjust to the new circumstances and return to psychological and social equilibrium (Horwitz \& Wakefield, 2007, p.16).

Horwitz and Wakefield thus think that normal grief does not count as a disorder because it involves no evolutionary dysfunction. If Wakefield's claims about functioning are correct, then a Boorsean would have to agree with him on this matter.

Horwitz and Wakefield also write, briefly, about complicated grief. Here they do think it reasonable to think that there is some evolutionary dysfunction, and thus they are happy to accept that complicated grief counts as a disorder. They write,

When grief involves extreme immobilisation, pronounced psychotic ideation, or severe symptoms that persist despite the passage of time and changing circumstances, then it can be presumed that an individual's reaction to the death of an intimate has caused a breakdown in his or her psychological functioning...such pathological states constitute Complicated Grief. (Horwitz \& Wakefield, 2007, p.33).

Following Wakefield, can we simply conclude that normal grief involves no dysfunction and thus is not a disorder, while complicated grief does involve some evolutionary dysfunction and thus is a disorder? Unfortunately not. This is what the accounts of Boorse and Wakefield imply, but there are reasons why many doubt that their accounts of the concept of disorder are correct. The key concern is whether it is indeed the case that all disorders have to be biological dysfunctions. The discipline of evolutionary psychopathology suggests that this may not be so - there may be some mental disorders that confer an evolutionary advantage and are thus not dysfunctions (Wilson, 1993). Psychopathy or generalised anxiety disorder, for example, may have an evolutionary explanation (Akiskal, 1998; Mealy, 1995). Of course, all evolutionary-based accounts of psychopathology are controversial. However, it at least makes sense to think that some disorders may have an evolutionary explanation and this is sufficient to show that it cannot be part of our concept of disorder that there has to be an evolutionary dysfunction. Wakefield's account implies that by definition all disorders would have to be evolutionary dysfunctions, but "Evolutionarily-adaptive disorder" is not an oxymoron. 
Given the criticisms of Wakefield's account some accounts of disorder have been developed that completely separate the question of whether a condition is a disorder from the question of whether there is an evolutionary dysfunction. A range of such accounts are on offer. Some claim that an individual is healthy if they have bodies and minds that will enable them to live good lives (at least if environmental and social conditions are favourable). To a first approximation, this is the view of Megone (1998, 2000), Nordenfelt (1995), and Richman (2004), although these philosophers differ in the details of their accounts and on how they characterise the good life. Other philosophers agree that disorders are necessarily bad states, but think that additional criteria must also be met before a condition can be considered a disorder. Reznek proposes that a disorder is an abnormal bodily or mental condition which requires medical intervention and which harms standard members of the species in standard conditions (1987, pp.163-4). He takes it that we decide what we will count as abnormal ("abnormal" functions as a call to action stating that we consider dealing with the harmful condition to be a priority), and that "medical interventions" can be defined enumeratively, via a list of possible pharmacological and surgical interventions (1987, p.94). Along similar lines, I have argued that by "disease" we mean a condition that it is a bad thing to have, that is such that we consider the afflicted person to be unlucky, and that can potentially be appropriately medically or psychologically treated (Cooper, 2002, 2005).

All these accounts hold that a condition can only be a disorder if it is a bad thing. On such accounts a key question in determining whether complicated grief (or normal grief) is a disorder is whether it is bad. At first glance, grief in all its varieties looks to be a bad thing. The grieving person feels unhappy and finds everyday tasks difficult. However, we should pause before concluding that we would be better off without grief. Grieving for a loved one does not simply involve negative affect, but also activities such as remembering the good times one has had. Paul Rosenblatt points out that “A bereaved parent may remember a child's laughter, the tender feelings of holding a sleeping infant, or a child's creative mischief. Thus recurrent grief is not like recurrent illness. It can be a link with the best of life.." (1996, p.55). Not only may grief involve mixed feelings, there are good reasons to think that grieving for a loved one is essentially tied-up with having loved him or her in the first place. The President's Council on Bioethics considers the possibility of medicating away grief and asks us to consider the following thought experiment (2003, pp.254-255). Suppose on your death nobody mourned. How would you feel if on your death your family and friends simply popped some pills and forgot about you? Would you consider this a good thing? Most people do not want their family and friends to simply move on. Those who are ungrieved in death were unloved in life. 
How is it that a capacity to love might be tied-up with a capacity to grieve? According to many accounts to have an emotion at one point in time commits one to other emotions in other circumstances (Helm, 2001). Thus, if I love my son then this commits me to feel various other emotions in various circumstances. If my son does well I will be pleased. If he is in danger I will be concerned. And, if he dies I will grieve. On such a picture, grieving for a dead loved one is rationally connected with having loved them in the first place. We might want to qualify this idea somewhat, as the death of a very old and ill person might be all things considered be a good thing, and here grief may be less apt. Plausibly, loving someone will only commit me to grieving his or her death if the death is regrettable. Nonetheless there will be a conceptual link between love and grief. Note that the link between grief and love here is supposed to be a rational connection, rather than being, say, a side-effect of our evolutionary heritage (for the idea that grief must be a sideeffect of our evolved ability to form attachments see Frances, 2010). The idea is that loving someone commits any rational being, whether they have the evolved vulnerabilities of humans or not, to feel grief in appropriate contexts. On this picture grief isn't some unfortunate side-effect but is essentially tied to our capacity to love.

Following on from such thoughts, Radden and Solomon both argue that the conceptual link between love and grief is such that grief is a moral emotion (Radden, 2009, p.102; Solomon, 2007, p.75). Grief on the regrettable death of a loved one is not only expected, or rationally appropriate, it is morally required. In appropriate circumstances, a virtuous person will feel grief, and one who doesn't grieve is condemned as callous (assuming that some pathology isn't preventing their grief).

I suggest that the idea that there is a conceptual link between loving someone and grieving when they die is on the right tracks but we need to be careful when thinking about exactly what is implied. In the normal case I will love someone when they are alive and then some time later, when they die, grieve for them. But suppose that something happens that prevents me from grieving - I die before the loved one, or come to suffer from severe dementia, or take medication that flattens my emotional responses. As all these things happen after the time when I loved, my love can't be affected by these later happenings - we should not countenance the possibility of backwards causation here. Thus we shouldn't say that if we love someone this implies that we must later grieve their death, but rather that if we love someone this implies that we will be vulnerable to later feeling grief (if we are still in a state that makes grief possible when they die). On such a picture, if I entered into relationships knowing that in the event of bereavement I would use drugs to take away feelings of normal grief, this would be problematic, as in so far as it removed the risk involved in 
loving, it would alter the nature of love. (In the same sort of way, rock climbing with ropes is a different type of activity from free climbing).

Suppose we accept that exposing ourselves to the risk of grief is an essential part of loving someone. Following such reasoning we might see normal grief as an essential risk in a good human life. Still only grief that is proportionate to the loss is conceptually tied to love. On such a picture we can imagine two types of problematic case. First, there is the person who grieves too little. Such a person is either suffering from a pathological condition - absent grief, or repressed grief, or whatever - or has some character flaw, such as callousness, and never truly loved in the first place. Second, there is the person who grieves too much or too severely. Such cases would be counted as cases of complicated grief.

Can we conclude that normal grief is a part of the flourishing human life and thus normal, while complicated grief is grief that is disproportionate and thus pathological? Unfortunately, matters are not quite so clear-cut, as problems emerge in determining whether grief is proportionate. How long should a person grieve? When I imagine my death, it seems to me both fitting and right that my partner would feel sad for about six months. But on reflection it can be no accident that this seems right to me! As an inhabitant of a twentyfirst-century European country this is what I've come to expect. However, we know that in some cultures the period expected for mourning is comparatively short, while in others a truly dedicated partner is expected to mourn for much longer (Stroebe, Gergen, Gergen \& Stroebe, 1996). Given that our expectations about normal grieving are clearly culturally-shaped, and given that determining how long one should grieve on some basis other than societal norms will be deeply problematic, distinguishing between normal grief and grief that is too intense or lasts for too long will be difficult. Normative accounts of disorder tell us that grief is not a disorder so long as it plays a proper part in enabling us to lead flourishing lives, but it is unclear how we might decide how much grief a flourishing human should feel. At bottom the question depends on decisions about the sorts of individuals we want to be and the sorts of societies we want to live in - and these are hard issues indeed. To make things yet harder, not only is determining the nature of the good life intrinsically difficult, complications arise when we reflect on the fact that our ideas about the good life are plausibly shaped by the economic and political structure in which we live. Contemporary Western culture idealises persons who are independent, happy, and reliable, and it is surely no accident that these characteristics are also those that enable an individual to be economically productive in an advanced capitalist society. Persons whose grief is "dis-ordered" are a liability in our society, and this will create additional pressures to medicalise the symptoms of unusually intense or long-lasting grief (Walter, 2006). Plausibly very severe and long-lasting grief is 
a bad thing, but drawing the line between the normal and the pathological is problematic.

So far we have considered accounts of disorder that specify criteria that must be met for a condition to count as a disorder. Boorse thinks that disorders are biological dysfunctions, Wakefield that disorders are harmful dysfunctions, and the other philosophers we considered hold that disorders must be harmful (and maybe meet some other criteria too). If we adopt one of these accounts then the way to find out whether complicated grief (or normal grief) is a disorder is to see if it meets the necessary and sufficient conditions. Following such reasoning, we have considered whether complicated grief, or normal grief, might be an evolutionary dysfunction, and whether these conditions are harmful or necessary components of a good human life.

Apart from the philosophical accounts of the concept of disorder that we have considered, there are also definitions that lie outside the philosophical traditions but that have been influential and much discussed. Most importantly, the DSM has included a definition of mental disorder since the publication of the DSM-III in 1980:

...each of the mental disorders is conceptualized as a clinically significant behavioural or psychological syndrome or pattern that occurs in an individual and that is typically associated with either a painful symptom (distress) or impairment in one or more areas of functioning (disability). In addition there is an inference that there is a behavioural, psychological, or biological dysfunction, and that the disturbance is not only in the relationship between the individual and society. (A.P.A., 1980, p.6)

In the DSM-III, uncomplicated grief is distinguished from depression by fiat. The diagnostic criteria for depression instruct clinicians that uncomplicated grief "is not considered a mental disorder even when associated with the full depressive syndrome" (A.P.A., 1980, p.213). Instead those individuals who manifest what may be a "full depressive syndrome" in the context of bereavement are to be given a V-code (i.e. a non-disorder code) (A.P.A., 1980, p.333). The DSMIII does, however, allow that bereavement may be "complicated by the development of a Major Depression" which may be diagnosed in bereaved persons who display very severe problems. By the DSM-IV, the reasoning behind excluding grief is made explicit and the definition of mental disorder has been revised to include a criterium specifying that the "syndrome or pattern must not be merely an expectable and culturally sanctioned response to a particular event, for example, the death of a loved one" (A.P.A., 1994, p.xxi). Proposals for the DSM-5 currently suggest that the grief exclusion clause will be removed from the criteria for Major Depressive Disorder. 
Proponents of this change reason that there is little to distinguish cases of depression that are caused by bereavement and those that are caused by other stressors (Kendler, 2010; Kendler, Myers \& Zisook 2008). Advocates have also lobbied for the inclusion of a new category of complicated grief, and current proposals for the DSM-5 suggest that criteria for Bereavement Related Disorder will be included in an appendix for further study.

In the philosophical literature, Wilkinson (2000) considers the DSM-IV definition of disorder and how it might apply to grief. He is especially critical of the DSM-IV's claim that an "expected and culturally sanctioned response to external events" should not be considered a disorder. Wilkinson notes that in physical medicine, injuries are generally "expected responses to external events" and yet also are considered as disorders. Following Engel (1961), Wilkinson asks us to compare grief to a burn, which is an expected response to burning in the same sort of way that grief is an expected response to the loss of a loved one. Engel and Wilkinson both suggest that we might conceive of grief as being a psychic injury. (Or alternatively, Wilkinson suggests that if we are convinced that normal grief is not a disorder then some approach other than the DSM way of defining disorder will be needed.) The concept of "psychic injury" has been little explored, and could usefully be considered further.

Finally, two philosophical accounts should be mentioned that both resist the notion that whether a condition is a disorder should be determined via asking whether some necessary and sufficient conditions obtain. Lilienfeld and Marino (1995) suggest that it is not possible to find an adequate definition of "mental disorder" because mental disorder is a Roschian concept (Rosch, 1978). A Roschian concept is one where no definition of the concept can be provided, but where we decide whether a particular case belongs to a category on the basis of its overall similarity to prototypical cases. In the case of "mental disorder", prototypical examples of mental disorders are schizophrenia and psychotic depression. Other conditions are classified as "mental disorders" if they seem similar enough to these prototypical mental disorders. On this account if we want to know whether complicated grief should be considered a disorder we should ask whether it is similar enough to conditions like psychotic depression and schizophrenia. On such an account, complicated grief would plausibly pass the test, and could fairly be considered a disorder.

In What is Mental Disorder? (2008) Bolton suggests that if we want to know when psychiatric treatment is justifiable then setting out by asking whether the condition is a disorder may not be the most useful approach to take. In his view, attempts to define the concept of mental disorder have failed. However, Bolton believes that psychiatry can justifiably continue to operate even in the 
absence of a satisfactory account of mental disorder. Bolton seeks to place the distressed patient at the heart of his account. The patients comes for help, and mental health professionals seek to help them in a way that is recognisably medical, as opposed, to, say, economic or educational. Determining when such interventions are appropriate depends on diverse factors, such as whether the problem is most effectively dealt with by medical or other means, and also ethical and political decisions regarding the sort of lives we wish to lead. Thus, on Bolton's view, the key questions will be whether complicated grief can be helpfully treated by health care professionals, and whether we think such treatments ethically justifiable. If Bolton is right, philosophical debates about the nature of mental disorder will turn out to be merely a distraction.

At this point one might be tempted to conclude that as philosophers cannot agree amongst themselves there is little to be learnt from them. However, I suggest that some useful pointers can be taken from the philosophical literature. We have seen that accounts of disorder are contested, but on all available accounts complicated grief will likely count as a disorder. While what counts as "normal mourning" varies from culture to culture, in so far as the symptoms of complicated grief go far beyond those of normal grief in intensity and duration there are good grounds to think that some evolutionary dysfunction might be involved. Furthermore, such a syndrome is plausibly not conducive to living a flourishing life. The symptoms of complicated grief are relevantly similar to those of conditions that are generally accepted to be disorders. Bolton, who is sceptical of the usefulness of the term "mental disorder", will also likely accept that complicated grief can justifiably be treated by health care professionals. We have only come across one potential reason to hesitate before concluding that complicated grief is a disorder; the distinction between grief that is considered appropriate and that which is excessive is not clear-cut but is culturally-shaped. Though this is a worry, I suggest that we are on safe ground if we hold that we can at least be certain that very severe symptoms cannot be conducive to a leading a good life, and can rightly be considered pathological.

The case of normal grief is more problematic. Those who hold that disorders must involve evolutionary dysfunctions may doubt whether there is any dysfunction here. Those with normative accounts of disorder may consider normal grief to be an essential component of a good human life. In so far as love and grief are conceptually connected, reducing our capacity to experience normal grief would reduce our ability to love. On the other hand, Wilkinson has suggested that we might think of normal grief as a "psychic injury" analogous to a burn, and this idea might be fruitfully explored further. 


\section{Part II - Is complicated grief a distinct disorder?}

In much of the literature arguing that complicated grief is a valid disorder the questions of whether complicated grief is a disorder and the question of whether it is a distinct condition from other conditions are run together. I suggest that these questions are best kept distinct. We can distinguish two sorts of question:

i. Is condition $\mathrm{X}$ genuinely a disorder - as opposed to some type of non-disorder condition, for example, a vice, or a normal variation, or a good variation? For example we might ask whether normal grief is pathological or a necessary component of a flourishing human life.

ii. Is condition $\mathrm{X}$ genuinely a different kind of condition from condition Y? For example we might ask whether complicated grief is distinct from MDD or PTSD.

The distinction between these two sorts of question can be made clearer by considering an analogy. Suppose we set out to classify weeds, and define "weeds" as unwanted plants. We will face many difficult questions. Are daisies weeds? What about blackberries? A classification that sets out to list all and only weeds will become mired in controversy. However, in parallel to these questions there will be other types of question that might prove easier to address: are blackberries really a distinct species from raspberries, for example? How should hybrid berries be classified? In the same sort of way that the question of whether a blackberry is a weed is distinct from the question of whether blackberries are of a different species to raspberries, so too the question of whether complicated grief is a disorder is a different question to whether complicated grief is a distinct condition to other conditions (MDD, PTSD, or whatever it might be).

How might we determine whether a condition should be considered distinct from other conditions? In their classic 1970 paper, Robins and Guze suggest that a condition can be considered distinct if it is shown to differ from other conditions in terms of phenomenology, etiology and correlates, outcome, clinical course, and response to treatment. Following such reasoning those who argue that complicated grief is best considered to be distinct from other conditions have sought to locate differences in these validators (Lichtenthal, Cruess \& Prigerson, 2004; Prigerson, Vanderwerker \& Maciejewski, 2008). Taking a somewhat different approach, Boelen and van den Bout (2005) use factor analysis to suggest that complicated grief, depression and anxiety are distinct syndromes. Meanwhile, Stroebe and Schut (2005-6) use a conceptual approach to argue that trauma and grief are overlapping but distinct (in so far as some peaceful deaths will not be traumatic, and some 
traumas do not result in death).

What might the philosophical literature contribute to such debates? I suggest that an account of classification proposed by Dupré may help us think about the relevant issues (1981, 1993). Dupré puts forward an account that he calls promiscuous realism. The key idea is that the world is a messy and complex place, and that depending on our interests we may usefully classify in diverse ways. Dupré asks us to imagine a multidimensional quality space in which the entities in some domain have been plotted (he considers biological organisms, but his ideas can be generalised). In such a space, entities that are similar will be found close together, while those that are very different will be found far apart. In the space it will be possible to find various clusters of entities that are highly similar to each other. We can expect the patterns of similarities to be highly complex - there will be clusters within clusters, groups of entities that cluster in certain dimensions, but not others, and so on. Thinking in terms of such a space, Dupré notes that there will be very many clusters that we might chose to pick out. Depending on our interests we might focus on certain dimensions, or focus in on greater or lesser degrees of resolution.

Dupré's picture is compatible with the reasoning employed in debates whether complicated grief is a distinct condition. Suppose one wants to argue that complicated grief should be considered a distinct condition. How should one reason? On Dupré's picture the important task is to demonstrate that cases of complicated grief differ from the other condition in some important respect phenomenology, treatment response, or whatever it might be. Such reasoning is indeed that adopted by those who wish to argue that complicated grief is a distinct condition. On the other hand, suppose one wants to argue that complicated grief should be classified alongside some other condition. Then the task is to show that complicated grief and the other condition are alike in some important respect.

The key insight provided by Dupré's account is that in general it is possible to produce multiple useful but incompatible classifications of some domain. The classification one will develop depends on the properties in which one is interested. Dupré (2001) discusses classification in biology. He notes that species can be defined in different ways, for example, by relations of ancestry or by current characteristics. Different ways of classifying focus on different properties and are most useful in different biological sub-disciplines. Evolutionary theorists will find it most useful to classify by patterns of ancestry; ecologists will find it more useful to classify on the basis of current characteristics. In such a situation, Dupré suggests that a thousand flowers should be allowed to bloom and that different sub-disciplines should be permitted to classify as they find most useful. 
On Dupré's picture, empirical data is of course relevant to decisions as to how complicated grief should be classified, but once all the empirical data is in, deciding whether complicated grief should be classified with other conditions or apart may be a matter for choice. It may turn out that both those who consider complicated grief to be a mere variant of some other disorder and those who consider it to be importantly distinct have fair points to make, and that proponents of the different positions merely concentrate on different features of the conditions. If this turned out to be the case, on Dupré's picture it would be permissible to employ different classifications for different purposes. For example, those interested in developing treatments might classify in one way, while those exploring the factors that make particular individuals vulnerable to developing the disorder might classify in another. There may be no one answer to the question of whether Complicated Grief should be considered a distinct disorder or a mere variant.

\section{Conclusion}

In this chapter I have explored how philosophical work might contribute to elucidating the concept of complicated grief. In Part I, I set out common philosophical accounts of disorder. Although accounts of disorder are contested, current prominent accounts suggest that complicated grief should be considered a disorder. In Part II, I considered whether complicated grief should be considered a distinct condition or merely a variant of some other condition. I suggested that insights taken from Dupré's work on Promiscuous Realism suggest that multiple answers to this question might be justified. The world is a complex and messy place and multiple conflicting classifications might prove useful for different purposes. For some purposes it may be helpful to consider complicated grief alongside other conditions, for others it might best be considered separately.

\section{Acknowledgements}

I am grateful to Alison Stone and the editors of this volume who read and commented on an earlier draft of this chapter.

\section{References}

American Psychiatric Association. (1980). Diagnostic and Statistical Manual of Mental Disorders. (3rd Edition). Washington: American Psychiatric Association. 
(Fourth Edition). Washington: American Psychiatric Association.

Akiskal, H. (1998). Toward a definition of generalised anxiety disorder as an anxious temperament type. Acta Psychiatrica Scandinavica Suppl, 393, 66-73.

Bayer, R. (1981). Homosexuality and American psychiatry. New York: Basic Books Inc.

Boelen, P., \& Van den Bout, J. (2005). Complicated grief, depression, and anxiety as distinct postloss syndromes: A confirmatory factor analysis study. American Journal of Psychiatry, $162,2175-2177$.

Bolton, D. (2008). What is mental disorder? Oxford: Oxford University Press.

Boorse, C. (1975). On the distinction between disease and illness. Philosophy and Public Affairs, 5, 49-68.

Boorse, C. (1976), What a theory of mental health should be. Journal for the Theory of Social Behaviour, 6, 61-84.

Boorse, C. (1977). Health as a theoretical concept. Philosophy of Science, 44, 542-573.

Boorse, C. (1997). A rebuttal on health. In J. Hunter \& R. Almeder (Eds.) What is disease? (pp.1134). Totowa, New Jersey: Humana Press.

Cooper, R. (2002). Disease. Studies in History and Philosophy of Biological and Biomedical Science,. 33, 263-282.

Cooper, R. (2005). Classifying madness: A philosophical examination of the Diagnostic and Statistical Manual of Mental Disorders. Springer: Dordrecht.

Dupré, J. (1981). Natural kinds and biological taxa. The Philosophical Review, XC, 66-90.

Dupré, J. (1993). The disorder of things. Cambridge, Massachusetts: Harvard University Press.

Dupré, J. (2001). In defence of classification. Studies in History and Philosophy of Biological and Biomedical Sciences, 32, 203-219.

Engel, G. (1961). Is grief a disease? A challenge for medical research. Psychosomatic Medicine, 23, $18-22$. 
Frances, A. (2010, August 15). Good grief. The New York Times.

Helm, B. (2001). Emotional reason. Cambridge: Cambridge University Press.

Horwitz, A. \& Wakefield, J. (2007). The Loss of sadness: How psychiatry transformed normal sadness into depressive disorder. Oxford: Oxford University Press.

Kendler, K. (2010). Notes on the proposed the deletion of the grief exclusion criterion from the criteria for Major Depression. Retrieved from http://www.dsm5.org/about/Documents/grief\%20exclusion_Kendler.pdf accessed 26.11.10

Kendler, K., Myers, J., \& Zisook, S. (2008).Does bereavement-related major depression differ from major depression associated with other stressful life events? American Journal of Psychiatry. 165, 1449-1455.

Lichtenthal, W., Cruess, D., \& Prigerson, H. (2004). A case for establishing complicated grief as a distinct mental disorder in DSM-V. Clinical Psychology Review. 24, 637-662.

Lilienfeld, S. \& Marino, L. (1995). Mental disorder as a Roschian concept: A critique of Wakefield's “Harmful Dysfunction” analysis. Journal of Abnormal Psychology. 104, 411420.

Mealey, L. (1995). The sociobiology of sociopathy: An integrated evolutionary model. Reprinted in S. Baron-Cohen (Ed.) (1997) The maladapted mind. (pp.133-189). Hove: Psychology Press.

Megone, C. (1998). Aristotle's function argument and the concept of mental illness. Philosophy, Psychiatry and Psychology. 5, 187-201.

Megone, C. (2000). Mental illness, human function and values. Philosophy, Psychiatry and Psychology. 7, 45-65.

Nordenfelt, L. (1995) On the nature of health: An action-theoretic approach. $2^{\text {nd }}$ edition revised. Dordrecht: Kluwer.

President's Council on Bioethics (2003) Beyond therapy: Biotechnology and the pursuit of happiness. Washington, DC. 
Prigerson, H., Vanderwerker, L., \& Maciejewski, P. (2008). A case for inclusion of prolonged grief disorder in DSM-V. Grief Matters. Autumn 2008, 23-32.

Radden, J. (2009). Moody minds distempered: Essays on melancholy and depression. Oxford: Oxford University Press.

Reznek, L. (1987). The nature of disease. London: Routledge and Kegan Paul.

Richman, K. (2004). Ethics and the metaphysics of medicine. Cambridge, Massachusetts: MIT Press.

Robins, E \& Guze, SB. (1970). Establishment of diagnostic validity in psychiatric illness: Its application to schizophrenia. American Journal of Psychiatry, 126, 983-987.

Rosch, E. (1978). Principles of categorization. In E. Rosch \& B. Lloyd (Eds.) Cognition and Categorization. (pp.27-48.) Hillsdale, New Jersey: Lawrence Erlbaum Associates.

Rosenblatt, P. (1996) Grief that does not end. In D. Klass, P. Silverman, \& S. Nickman (Eds.). Continuing bonds: New understandings of grief. (pp45-59) Philadeplhia: Taylor and Francis.

Solomon, R. (2007). True to our feelings. Oxford: Oxford University Press.

Spitzer, R. (1999). Harmful dysfunction and the D.S.M definition of mental disorder. Journal of Abnormal Psychology. 108, 430-432.

Stroebe, M. \& Schut, H. (2005-6). Complicated grief: A conceptual analysis of the field. Omega, $52,53-70$.

Stroebe, M., Gergen, M., Gergen, K. \& Stroebe, W. (1996). Broken hearts or broken bonds? In D. Klass, P. Silverman, \& S. Nickman (Eds.). Continuing bonds: New understandings of grief. (pp. 31-44). Philadeplhia: Taylor and Francis.

Wakefield, J. (1992a.). The concept of mental disorder - On the boundary between biological facts and social value. American Psychologist. 47, 373-388.

Wakefield, J. (1992b.). Disorder as harmful dysfunction: A conceptual critique of D.S.M-III-R's definition of mental disorder. Psychological Review. 99, 232-247. 
Wakefield, J. (1993). Limits of operationalization: A critique of Spitzer and Endicott's (1978) proposed operational criteria for mental disorder. Journal of Abnormal Psychology. 102, 160-172.

Wakefield, J. (1999). Evolutionary versus prototype analyses of the concept of disorder. Journal of Abnormal Psychology. 108, 374-399.

Walter, T. (2006). What is complicated grief? A social constructionist answer. Omega. The Journal of Death and Dying. 52, 71-79.

Wilkinson, S. (2000). Is 'normal grief' a mental disorder? The Philosophical Quarterly. 50, 289304.

Wilson, D. (1993). Evolutionary epidemiology: Darwinian theory in the service of medicine and psychiatry. Reprinted in S. Baron-Cohen (Ed.) (1997) The maladapted mind (pp.39-5). Hove: Psychology Press. 